\title{
A review on factors for maximizing solar fraction under wet climate environment in Malaysia
}

\begin{abstract}
Solar energy is the most promising source of clean, renewable energy and it has the greatest potential of any power source to solve the world's energy problems. However, the problem, is how best to harness this vast amount of solar energy. Nevertheless, even if highly efficient Concentrating Solar Power (CSP) could be made cheaply, there would be considerable change in solar power. This technology is expected to be more efficient and to achieve a manufacturing cost of less than $\$ 1 / \mathrm{W}$ near future. This paper reviews and elaborates the methodology utilized to design and fabricate the solar dish concentrator and outlines the parameters that can be used to increase the efficiency of solar fraction in parabolic dish concentrator under wet climate environment in Malaysia. The study finally provides ideas to the continually increasing ability of these technologies to concentrate and harness solar energy for electricity production and thus eliminate the growing concern over climate change and how it will hurt the region's environment, human health and economy.
\end{abstract}

Keyword: Renewable energy; CSP; Solar dish concentrator; Solar fraction; Climate change 